\section{Dialogando con la Luz. Este es un diálogo a cuatro voces, todas diferentes, procedentes del mundo de las ciencias naturales, matemáticas y físicas y del mundo del arte y del diseño \\ Marina Nova ${ }^{(1)}$, Marco Mancin (2), Marcela Cabutti ${ }^{(3)}$ y Emanuele Ricci ${ }^{(4)}$}

\begin{abstract}
Resumen: Una naturalista, un físico, un diseñador y una artista dialogan aportando sus experiencias y habilidades sobre un tema transversal como lo es la luz, las formas a través de las cuales los seres vivos la perciben y los colores que derivan de ella. Un rayo luminoso que llega a la Tierra se encuentra inmerso en una nueva dimensión: se lanza desde las cimas de las montañas a la profundidad marina "coloreando" la vida de los hombres. La luz vincula muchos aspectos de nuestra vida cotidiana. Así como la luz que podemos captar con nuestros ojos está formada por 7 colores, el aporte de cada uno de nosotros traerá un pequeño pixel para construir una única imagen. Desde lejos verán el conjunto, de cerca la trama y la urdimbre que cada uno de nosotros habrá tejido.
\end{abstract}

Palabras clave: Forma - Luz - Color - Proyecto - Lámpara - Ojo - Radiación - Visión Animales

[Resúmenes en inglés y portugués en las páginas 174-175]

(1) Marina Nova, nació en Milán el 01/08/1962, se licenció en Ciencias Naturales en la Universidad de Milán; en 1997 obtuvo un Máster en Diseño y Biónica en el Instituto Europeo de Diseño de Milán. Actualmente es profesora titular de la cátedra de Ciencias Naturales en el Liceo Artístico Estatal de Brera en Milán. Con un grupo de docentes de las disciplinas artísticas, crea una sinergia de intenciones que desemboca en recorridos educativos y exposiciones temporales realizadas con estudiantes de secundaria sobre temas que vinculan la naturaleza con el arte. Zoóloga, creadora y coordinadora de GuardaMI, un proyecto de ciencia ciudadana en asociación con la Escuela de Arte de Brera, el Museo de Historia Natural de Milán, sobre el estudio de la biodiversidad de una ciudad dinámica y en constante cambio como Milán. Es colaboradora del Museo Cívico de Historia Natural de Milán para el diseño y construcción de un itinerario expositivo sobre el Hombre y el Medio ambiente. En los años 90 fue consultor científico en el Centro de Investigación IED de Milán para buscar soluciones en la Naturaleza para trasladarlas al mundo artificial y colaborar con diseñadores para proyectos relacionados con la Biónica. Como comunicadora científica realiza conferencias para el público sobre temas relacionados en particular 
con las aves, la geometría en la naturaleza y la relación entre arte y naturaleza. marinova@ rocketmail.com

${ }^{(2)}$ Marco Mancin, nacido en 22/08/1972, obtuvo una Maestría en Física en la Universidad Estatal de Milán. En la actualidad se desempeña como profesor de Matemáticas y Física en el Liceo Artístico Estatal de Brera en Milán. Es Investigador de posgrado en la Universidad de Milán-Bicocca, centro de excelencia Plasmaprometeo: El plasma representa el cuarto estado de la materia después de sólido, líquido y gaseoso. Al suministrar energía a un gas, los electrones se separan de los iones y se convierte en un estado de plasma. Una aplicación de los procesos de plasma es la funcionalización de los materiales: interactuando con la superficie del sustrato y mediante gas y precursores apropiados, se modifica o mejora el comportamiento químico-físico de los propios materiales. Como parte de las actividades desarrolladas, se profundizó sobre aspectos de diversas fuentes de plasma orientadas a la transferencia tecnológica de procesos plasmáticos desde la escala de laboratorio a la preindustrial. Análisis por microscopio electrónico y haz de iones [FIB / SEM] Análisis con ángulos de contacto [modalidad estática y dinámica].marco.mancin@gmail.com

${ }^{(3)}$ Marcela Cabutti, nació en 1967 en La Plata, Argentina. Se graduó en 1994 de la Facultad de Bellas Artes de la Universidad Nacional de La Plata en Escultura e Historia del Arte. En 1995-96 recibió una beca de la Fundación Antorchas para participar del taller Barracas con los artistas Luis F. Benedit y Pablo Suárez en el que creó esculturas, objetos e instalaciones. La Fundación Antorchas también apoyó el su estudio en 1998 en Diseño y Biónica en el Instituto Europeo de Diseño de Milán, Italia. En ese año participó de la residencia en el Delfina Studio Trust, Londres. En 2000 realizó las residencias en Duende Ateliers, Rotterdam y en el Columbus College of Art and Design (Ohio), donde se desempeñó como artista residente de vidrio La relación Arte, Ciencia y la Naturaleza son los conceptos sobre los cuales reflexiona en sus obras abordadas desde diversas materialidades y con colaboradores externos de diversas disciplinas de modo de ampliar los campos de observación y aprendizaje. La artista es docente en Facultad de Bellas Artes Universidad Nacional de La Plata (desde 1991) y directora de Tesis en la UNLP La Plata (desde 2012). Coordina además la Residencia de Artistas para el Museo del Ladrillo. Programa Arte e Industria. Fundación Espacio Ctibor, La Plata (desde 2013).mcabutti@yahoo.com.ar

${ }^{(4)}$ Emanuele Giovanni Ricci, nació en la provincia de Treviso, Italia en 1963. Después de graduarse en la Escuela Superior de Agricultura Conegliano Veneto, estudió en la Scuola Politecnica di Design de Milán y pasó un período de formación en el estudio del arquitecto Gianfranco Frattini, luego comenzó su actividad como diseñador. El idealismo y la investigación son la base de su pensamiento. Gracias a sus estudios en el campo de la botánica, la entomología y la búsqueda tecnológica, es capaz de decodificar y transferir en sus proyectos muchos fenómenos del mundo natural. En treinta años de trabajo ha desarrollado un lenguaje propio, donde la modulación de la luz a través de las formas y la investigación técnica juegan un papel importante. En 2015 fundó, con Alessandro Alberti, Enhance Vision System (EVS), una start-up innovadora, que desarrolla y patenta un dispositivo óptico que puede eliminar el punto ciego generado por el pilar a de un vehículo, 
sin comprometer su seguridad estática del miso. Alterna su actividad como diseñador en su estudio de Milán, con períodos de retiro en las colinas del norte de Treviso donde elabora su investigación artística. Ejerce la docencia en institutos italianos y europeos. io@emanuelericci.com

Cuando un rayo de luz atraviesa un prisma se descompone en sus componentes fundamentales. En este artículo se parte de la visión de un aspecto de la naturaleza y se descompone en algunos discursos a través de la visión de cuatro amigos con formaciones diferentes: un artista, un diseñador, una naturalista y un físico. Dada la complejidad de la Naturaleza, las nuestras son sólo algunas de las consideraciones posibles sobre un tema amplio y complejo como es la Luz. Nuestra intención es mostrar que, para decodificar la realidad y para obtener una imagen completa, se necesitan distintos puntos de vista. Está claro que los "puntos de vista" no son opiniones, sino ideas que se basan en el estudio y en las experiencias que cada uno de nosotros ha desarrollado en su profesiones (Figura 1).

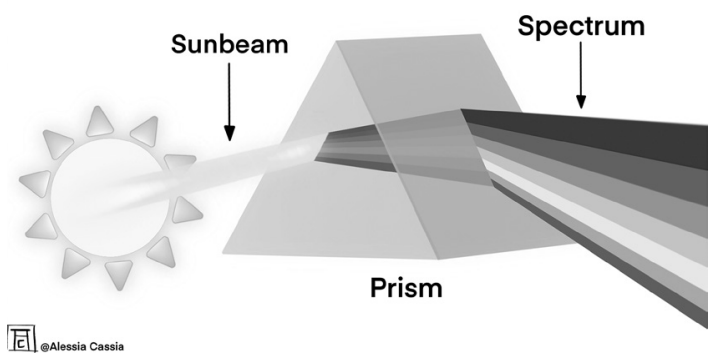

Figura 1. La

dispersión: descomposición de la luz blanca en sus componentes fundamentales.

\section{Introducción de la naturalista}

Soy una naturalista y he trabajado durante años con diseñadores, arquitectos y artistas en el IED (Instituto Europeo de Diseño) de Milán, donde obtuve el Máster en Biónica y aprendí a ir más allá de la información científica de mi mundo, para encontrar un universo nuevo donde el componente natural se vuelve una provocación, un acicate o un elemento para la proyectación. La luz es objeto de interés común para todos nosotros. La luz y su opuesto, la oscuridad, se alternan a lo largo del día o de las estaciones, influyendo en el medio ambiente y en los 
ritmos de vida de los organismos. Los seres vivientes a lo largo de su historia han desarrollado así sistemas para captar la luz y crearse imágenes de su mundo.

Estoy acostumbrada a estudiar aquello que mis ojos ven: la Naturaleza es un caleidoscopio de formas y colores que se diferencian en la biodiversidad de los organismos que se suceden a lo largo de la evolución. ¿Cómo adquiere una especie capacidades completamente nuevas o reorganiza las características de capacidades ya existentes? Hay ejemplos muy intrigantes que se refieren al origen y a la evolución de la visión en color de los animales. La posesión y la regulación de este sentido es fundamental para su estilo de vida, para aprovisionarse de comida, para encontrar con quién aparearse entre los de la misma especie, en la luz del día o en la oscuridad de la noche o en las profundidades marinas.

Por una vez quiero mirar el proceso evolutivo desde el interior y no desde el exterior y por eso es necesario entrar en la intimidad del DNA de una especie, o sea, en el conjunto de genes usados para construir y caracterizar dicho organismo. Comparando los genes y las herencias genéticas entre grupos emparentados es posible individualizar cambios importantes y nuevas adaptaciones en la larga y fascinante historia de la vida. Los pasos necesarios para la adqusicición y la regulación de la visión en colores, acaecida en el DNA, demuestran la acción de la selección natural en la secuencia de genes a lo largo de la evolución.

\section{Introducción del artista}

Para la humanidad, el sentido de la vista es fundamental, incluso es uno de los sentidos que privilegiamos en nuestro proceso de vinculación con el entorno. Pensando particularmente en el campo artístico, la renovación del lenguaje del arte generado a partir de las vanguardias históricas, permitieron la experimentación con dispositivos materiales que aún hoy otorgan preponderancia al género de la pintura como medio de expresión. El abordaje desde distintos pensamientos materiales, me permiten experimentar sucesivamente en un contínuo pensar "con las manos".

Como artista y docente en la Universidad de La Plata, la experiencia en el Master en Biónica en el Cried (Instituto Europeo de Diseño) de Milán, me permitió abordar los objetos desde miradas multidisciplinares, donde la biónica y la biología fueron campos fundamentales. Metodología y abordajes que intentaremos proponer a lo largo de este artículo.

\section{Introducción del físico}

La física utiliza la matemática como lenguaje. En pocas palabras la práctica resume el fenómeno físico investigado, que suele adaptarse a la realidad y permite un análisis puntual y preciso. Formalizar un fenómeno natural y describirlo en términos matemáticos le permite al objeto vivir en diferentes mundos. El mundo natural del que deriva, el mundo racional que existe dentro de nuestro cerebro y el mundo matemático en el que, utilizando el lenguaje oportuno, se analizará, según la sensibilidad del lector. La matemática y la física, al igual que 
las otras disciplinas tienen momentos diferentes, en los que es imprescindible el acto creativo. Por un momento pensemos en un pintor o en una pintora con un lienzo y millones de colores a su disposición: ¿cuánto tiempo podría resistir sin dar rienda suelta a su arte? De la misma manera un físico podría limitar las fórmulas al mínimo, pero de vez en cuando, una o dos de esas deberán ser explicitadas, sino parecería que puede defraudar al lector. Afirmo algo y doy la posibilidad de verificarlo y de hacerlo propio a través de una fórmula.

La matemática, la física, las ciencias naturales, el arte, las letras, la historia entre otras, son instrumentos para entender la realidad y para entendernos nosotros mismos. Ante un problema nuestro cerebro reacciona echando mano de todo nuestro saber, sin hacer distinciones entre las disciplinas, y escoge el instrumento o los instrumentos más idóneos para buscar la solución ideal. Podemos escoger qué instrumentos llevar consigo toda la vida; cuantos más instrumentos tengamos, más fácil será vivir.

Los temas tratados en este artículo abarcan una parte francamente importante y copiosa de la física. La invitación es que estas pocas líneas puedan suscitar la curiosidad del lector. La esperanza es que el lector desee profundizar los temas que aquí se presentan rápidamente. Que nadie se desanime por el lenguaje, que nadie se desanime por las ecuaciones.

\section{Introducción del diseñador}

La luz siempre ha sido un elemento fundamental en mi camino de diseñador, sea como elemento físico o como lógico. Desde mi primera experiencia como diseñador de lámparas, me di cuenta de que la luz no es solamente una fuente luminosa, sino también una radiación, un volumen, una superficie y una forma. Entendí que vemos un objeto solo como el mismo refleja la luz a nuestros ojos. Entonces empecé un recorrido transversal que me llevó a encarar temas al parecer desvinculados entre sí: desde los aparatos de iluminación a los tejidos y profundizando cada vez más en el detalle, en las superficies para los tableros de los coches, a los gofrados para el papel y las superficies para la piel sintética; sin olvidar nunca las formas y los volúmenes de los objetos. Todos estos mundos viven gracias a la intima interacción entre luz y superficie. Mundos que nunca hubiera podido abordar sin este punto de referencia luminoso.

\section{La magia del arcoiris}

Podemos percibir los colores y sus infinitos matices gracias a una sofisticada serie de moléculas que captan la luz en las células de nuestra retina y gracias a las conexiones de estas últimas con el cerebro. Los otros animales tienen las mismas o distintas moléculas que se regulan para percibir intervalos diferentes del espectro luminoso. Para comprender qué pueden ver los animales es necesario ante todo definir la luz y qué determina los colores y en segundo lugar cuáles son las moléculas capaces de percibir la luz y las células del ojo que acogen imágenes en color. 


\section{Encuentro con la luz}

Ante todo consideramos luz como algo que el ser humano puede percibir a través de los ojos. La luz se propaga en el vacío y en los medios transparentes. El rayo luminoso es un modelo. Sucede con frecuencia que, como primer enfoque, se intente simplificar el fenómeno que se está estudiando.

La luz es una onda electromagnética, es decir, una perturbación generada por la interacción entre un campo eléctrico y un campo magnético. La intensidad de los dos vectores son perpendiculares entre ellos y generan una señal que se propaga perpendicularmente a ambas. Si E oscila en la dirección Y y B oscila en la dirección Z entonces la onda luminosa se propaga en la dirección X (Figura 2).

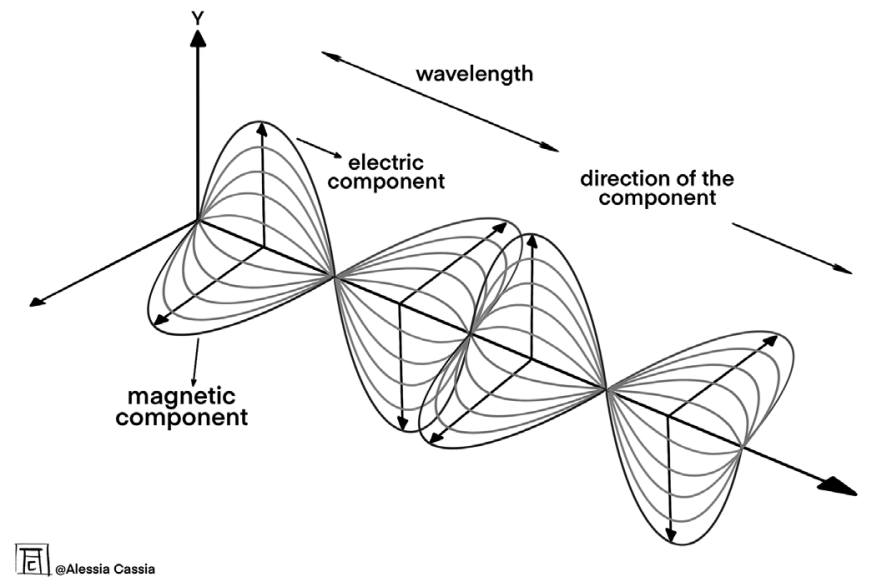

Figura 2. La luz como interacción entre campo eléctrico y magnético.

$\mathrm{Al}$ igual que todas las ondas se caracteriza por algunos parámetros físicos que la describen, como la amplitud, la longitud de onda, el periodo y la frecuencia. La amplitud y la variación máxima de la posición de equilibrio, la longitud de onda, lambda $(\lambda)$, (Figura 3) es la distancia entre dos puntos homólogos de la onda, por ejemplo dos máximos en la figura distancia entre $\mathrm{M}$ y N, (Figura 4) el periodo T de una onda es el intervalo de tiempo tras el cual el modelo empieza a repetirse y la frecuencia se define como el inverso del periodo, es decir, es el número de oscilaciones en la unidad de tiempo que se mide en segundos a la menos uno, o sea, los hertz $[\mathrm{Hz}]$. Desde un punto de vista matemático podemos representar una onda como una función sinusoidal, es decir, utilizando la función seno de un ángulo. 


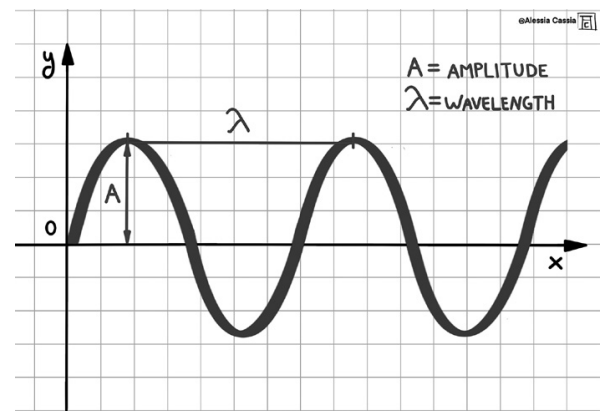

3

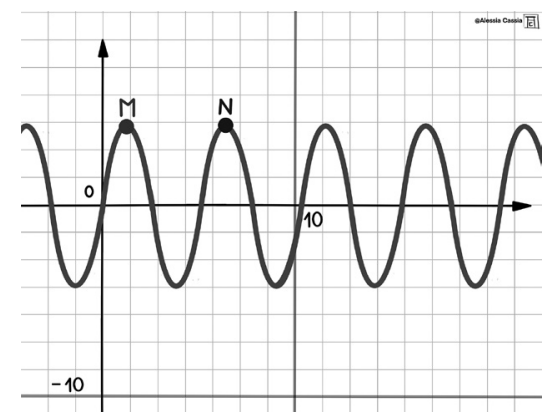

4

Figura 3. Las magnitudes de una onda. Figura 4. Onda sinusoidal.

A través de nuestros ojos podemos captar sólo una pequeña parte de las ondas electromagnéticas. El conjunto de todas las ondas electromagnéticas toma el nombre de "espectro electromagnético" (Figura 5).

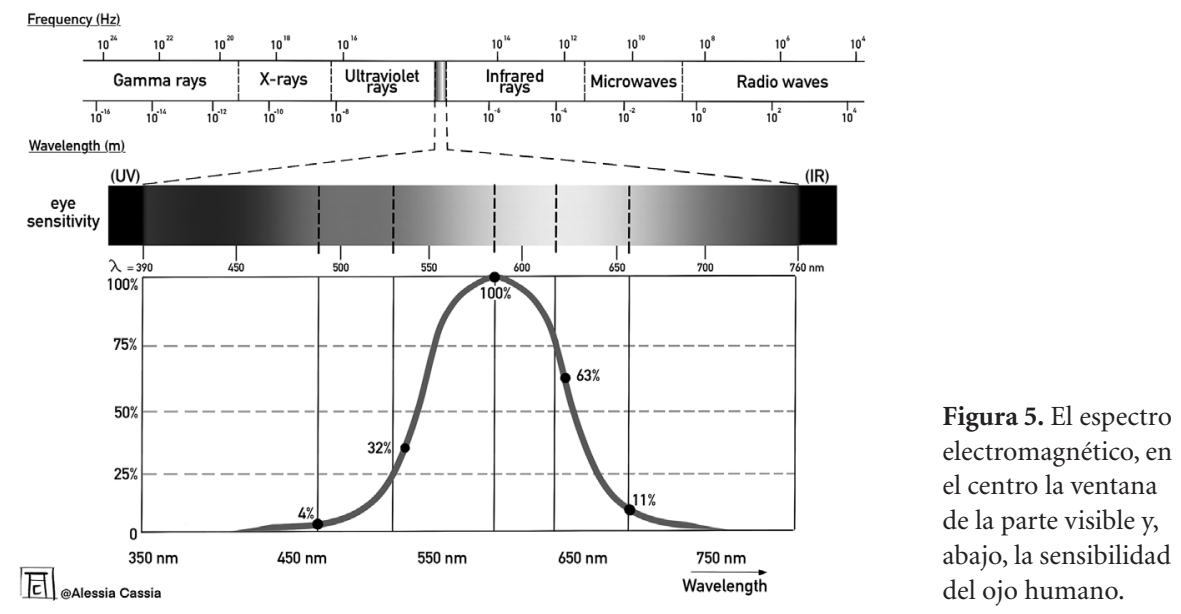


Podemos disponer las diferentes ondas sobre una recta hipotética en la que, a medida que nos movamos hacia la derecha aumente la energía transportada por la señal electromagnética. Se parte de las ondas radio (ondas largas) y se llega a los rayos gamma pasando por la parte visible del espectro. Con esta referencia la longitud de onda disminuye y la frecuencia aumenta yendo siempre hacia la derecha.

La pequeña ventana que podemos captar con los ojos representa el espectro visible de las ondas electromagnéticas. Se nota en la imagen que aquí se presenta que el ojo humano tiene un umbral de sensibilidad en correspondencia con el amarillo-verde. En ausencia de obstáculos la luz se propaga en línea recta. Por eso si encuentra un espejo el rayo se refleja. El ángulo de incidencia es igual al ángulo de reflexión (Figura 6).

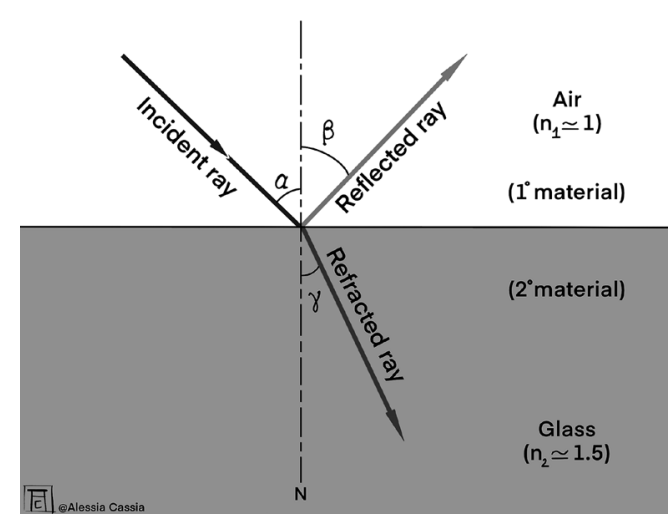

Figura 6. Reflexión (zona superior, primer medio) y refracción (zona inferior, segundo medio).

La interacción entre la onda luminosa y el medio material provoca una variación en la propagación de la velocidad de la onda. Dicha variación queda formalizada por el índice de refracción. Se trata de un número puro dado por la relación entre la velocidad de la luz en el vacío $c$ y en el medio $v$ (ver Ecuación 1):

Ecuación $1 \quad \mathrm{n}=\mathrm{c} / \mathrm{v}$ 